\title{
Prognostic Implication of Urothelial Stem Cell Markers Differs According to Primary Tumour Location in Non-Muscle-Invasive Bladder Cancer
}

\author{
Longwang Wang ${ }^{a, b}$ Jun Zhao ${ }^{a}$ Chenlu Yang ${ }^{a, c}$ Renrui Kuang ${ }^{b}$ \\ Gallina Kazobinka ${ }^{a}$ Zili Pang ${ }^{a}$ Teng Hou ${ }^{a}$
}

aDepartment of Urology, Union Hospital, Tongji Medical College, Huazhong University of Science and Technology, Wuhan, 'bepartment of Urology, The Second Affiliated Hospital of Nanchang University, Nanchang, 'Womem and Children Hospital of Guangdong Province, Guangzhou, China

\section{Key Words}

NMIBC $•$ Stem cell marker $\bullet$ RFS $・$ Trigone $\cdot$ Posterior wall

\begin{abstract}
Background/Aims: This study aimed to validate the value of urothelial stem cell (USC) markers $\triangle N p 63$, integrin $\beta 4, C D 47$, and CD44v6 in predicting the prognosis of non-muscle invasive bladder cancer (NMIBC) located in different anatomic regions of bladder. Methods: The study reviewed the clinicopathologic data of 169 patients with NMIBC. Using real-time PCR and immunohistochemistry, the expression of $\triangle N p 63$, integrin $\beta 4, C D 47$, and CD44v6 in archived specimens of patients with NMIBC were validated. Kaplan-Meier analysis and Cox proportional hazards model were used to assess the prognostic impact of USC markers for recurrent-free survival (RFS). Results: The Real-time PCR data showed that the expression of USC markers were higher in tumors located in the trigone and posterior wall than that in other regions of bladder $(P<0.05)$. Statistical analysis showed that high expression of $\Delta N p 63$ was correlated with tumor stage $(P=0.023)$ and tumor size $(P=0.001)$, that high expression of integrin $\beta 4$ was correlated with tumor stage $(P=0.026)$, tumor grade $(P=0.005)$ and tumor size $(P=0.003)$, and that high integrin $\beta 4, C D 47$, and $C D 44 v 6$ expression were significantly associated with tumor recurrence $(P=0.032, P=0.010$, and $P=0.043$, respectively). Moreover, high expression of $\Delta N p 63$ and integrin $\beta 4$ was correlated with poor RFS in patients with tumors located in the trigone $(P=0.025$ and $P=0.023$, respectively). High expression of integrin $\beta 4, C D 47$, and $C D 44 v 6$ was correlated with poor RFS in patients with tumors in the posterior wall $(P=0.017, P=0.033$ and $P=0.047$, respectively). High expression of integrin $\beta 4$ and CD47 was correlated with poor RFS in patients with tumors in the trigone/posterior wall area ( $P=0.002$ and $\mathrm{P}=0.005$, respectively).
\end{abstract}

Longwang Wang, Jun Zhao and Chenlu Yang contributed equally to this work.

Dr. Teng Hou

and Dr. Zili Pang
Department of Urology, Union Hospital, Tongji Medical College,

Huazhong University of Science and Technology; Wuhan, HB 430022, (China)

Tel.+86 138-71591704, E-Mail 1aiyan@163.com; zilipang21@163.com 
Conclusion: Our results suggest that USC markers are linked with poor prognosis of NMIBC patients, especially in patients with tumors in the trigone and posterior wall.

(C) 2018 The Author(s)

Published by S. Karger AG, Basel

\section{Introduction}

Bladder cancer is the second most prevalent genitourinary malignancy with greater than 429, 000 new cases and 165, 000 deaths per year worldwide [1]. In the course of their disease, up to $85 \%$ of patients present with lesion confined to the mucosa or submucosa, which is commonly termed non-muscle invasive bladder cancer (NMIBC) [2]. Even with maximum treatment, up to $45 \%$ of these patients will have tumor recurrence [3]. One major goal in treating NMIBC is to prevent the high number of recurrences [4]. Therefore, it is important to identify biomarkers to predict tumor recurrence of these patients as early as possible.

Increasing evidence suggests stem cell (SC) markers might be useful in predicting the clinical prognosis of human cancers, as many marker gene products found in stem cells are shared with the cancer stem cell (CSC) population, which is responsible for key elements of cancer progression, metastasis, and recurrence [5, 6]. In addition, SC markers have been used for the identification and isolation of putative SCs or CSCs. Urothelial stem cells (USC) have attracted considerable attention due to their possible roles in urothelium homoeostasis and tissue repair as well as their potential in tumor initiation $[7,8]$. In line with this notion, recent experiments have shown striking morphological and antigenic similarities between basal and intermediate differentiated cells and the corresponding cells in urothelial carcinomas [9]. Signalling pathways involved in USC self-renewing and cell differentiation are also implicated in the malignant transformation of urothelial carcinomas $[10,11]$. Therefore, understanding the expression and properties of specific USC markers may help improving our knowledge of urothelial biology and tumorigenesis.

Several biomarkers including $\Delta N p 63$, integrin $\beta 4, C D 47$, and CD44v6 have been reported as putative USC markers. $\triangle \mathrm{Np} 63$, the N-terminal truncated isoform of $\mathrm{p} 63$, is involved in normal development of several epithelial tissues, including the bladder and prostate glands, and $\Delta$ Np63-positive cells represent the stem/progenitor cells of bladder epithelium during development [12]. $\Delta$ Np63 isoform also account for p63 protein expression in normal and neoplastic urothelial tissue. In low-grade papillary bladder cancer, p63 expression was mainly in the basal layer as well as in normal bladder epithelium, whereas it was frequently undetectable in high-grade invasive cancer cells. Strikingly, impaired $\Delta$ Np63 expression correlated with a poor prognosis of invasive urothelial neoplasms [13]. Kurzrock et al. identified label-retaining cells (LRCs) in the bladder epithelium using a BrdU pulse-chase assay, and found that the urothelial LRCs population had a uniquely high expression of integrin $\beta 4$ [14], whose expression was significantly related to tumor differentiation and depth of invasion in bladder carcinomas [15]. Chan et al. demonstrated that CD47 is highly expressed in bladder tumor-initiating cells, and could inhibit macrophage engulfment of bladder cancer cells in vitro [16]. In addition, the tumorigenic potential of CD44+ cancer cells in immunocompromised mice was significantly enhanced compared with that in CD44- cells [16]. In vitro colony-forming assay also showed that the CD44 splice variant CD44v6 was enriched in bladder cancer stem cell subpopulations [17].

Investigation of the morphological structure and mRNA levels in different regions of bladder has revealed that the molecular organization of the urothelium was different in each bladder region $[18,19]$. Moreover, high concentration of urothelial progenitor cells was found to be present in the bladder trigone [20], further implying that the processes underlying stem cell mediated bladder tumorigenesis and tumor development may vary in different topographic regions of the bladder. Therefore, we hypothesised that the significance of USC markers may not be universal amongst NMIBC but may be region specific. In order to assess the prognostic role of USC markers in NMIBC, we divided the tumors into 6 subgroups according to their anatomic region (trigone, posterior wall (PW), right wall (RW), left wall 


\section{Cellular Physiology Cell Physiol Biochem 2018;48:2364-2373

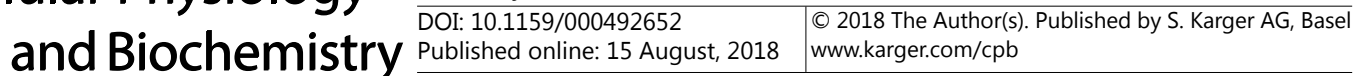 \\ Wang et al.: USC Markers Predict RFS of NMIBC in Different Areas}

(LW), anterior wall (AW), and dome) and stratified all analyses by USC markers expression pattern.

\section{Materials and Methods}

\section{Patients and tissue specimens}

This study collected data from a total of 169 NMIBC patients presenting with a single tumor in the bladder. None of the patients had a prior history of transitional cell carcinoma (TCC). The material was retrieved from archival paraffin-embedded surgical samples at The Second Affiliated Hospital of Nanchang University between Jan 2005 and December 2010. In addition, 60 snap-frozen bladder cancer and paired normal bladder samples (10 pairs for each region) from above patients were collected for Real-time PCR. None of the patients received preoperative chemotherapy or radiation therapy. All patients received transurethral resection of bladder cancer and postoperative instillation of intravesical chemotherapy (50 mg pirarubicin was given once a week for 8 weeks followed by once a month for 10 times), according to the national guidelines. For the use of these clinical materials for scientific purposes, prior written consent was obtained from all patients and this study was approved by the Research Ethics Committee of The Second Affiliated Hospital of Nanchang University.

\section{RNA Extraction and Real-time PCR}

Total RNA from bladder cancer and paired normal bladder tissues was extracted using Trizol reagent (Invitrogen, Carlsbad, CA, USA) according to the manufacturer's instructions [21]. The extracted RNA was pretreated with RNase-free DNase, and $2 \mu \mathrm{g}$ RNA from each sample was used for cDNA synthesis with random hexamers. Real-time PCR was performed using the Applied Biosystems 7500 Sequence Detection system with a SYBR Green Real-Time PCR Master Mix (Invitrogen, Carlsbad, California, USA). The primers used are as follows: $\triangle$ Np63, forward, 5'- GAAAACAATGCCCAGACTCAATTT-3', reverse, 5'- TCTGCGCGTGGTCTGTGTTAT-3'; integrin $\beta 4$, forward, 5'-CCTCATGGATGGTCTAACCC-3' , reverse, 5'-TGAGTGCTGAGAGAGCCACT-3'; CD47, forward, 5'-GGCAATGACGAAGGAGGTTA-3', reverse, 5'- ATCCGGTGGTATGGATGAGA-3'; CD44v6, forward, 5'-TTACAGCCTCAGCAGAGCAC-3', reverse, 5'-TGACCTAAGACGGAGGGAGG-3'; GAPDH, forward, 5'-AGAAGGCTGGGCTCATTTG-3', reverse, 5'-AGGGGCCATCCACAGTCTTC-3'. The expression level of USC markers mRNA was calculated using a ratio of USC markers mRNA to GAPDH mRNA.

\section{Immunohistochemistry}

In brief, paraffin-embedded specimens were cut into $4 \mu \mathrm{m}$ sections and baked at $65^{\circ} \mathrm{C}$ for 30 minutes. The sections were then deparaffinized in xylene and rehydrated. The sections were treated with $3 \%$ hydrogen peroxide in methanol to quench the endogenous peroxidase activity, followed by incubation overnight with monoclonal rabbit antibody against $\Delta \mathrm{Np} 63$ (BioLogo, Kronshagen, Germany; 1:100), monoclonal mouse antibody against integrin $\beta 4$ (Abcam, Cambridge, USA; 1:250), polyclonal rabbit antibody against CD47 (Abcam, Cambridge, USA; 1:200), and monoclonal rabbit antibody against CD44v6 (Abcam, Cambridge, USA; 1:150). Human cervical carcinoma tissues was used as positive control for integrin $\beta 4$, and CD44v6 staining, while human prostate tissues was used as positive control for $\Delta \mathrm{Np} 63$ and CD47. Negative controls were obtained by excluding the primary antibody. After washing, the sections were incubated with prediluted secondary antibody (Abcam, Cambridge, USA), followed by further incubation with 3, 3-diaminobenzidine tetrahydrochloride (DAB).

\section{IHC Scoring}

The degree of immunostaining was evaluated by two independent observers who were blind to the clinical data of the patients. The scores were determined by combining the proportion of positively stained tumor cells and the intensity of staining [22]. Intensity of stained cells was graded semi-quantitatively into four levels: 0 (no staining); 1 (weak staining = light yellow); 2 (moderate staining = yellow brown) and 3 (strong staining $=$ brown); and the proportion was scored as: 0 , negative; $1,10 \%$ or less; $2,11 \%$ to $50 \% ; 3$, $51 \%$ to $80 \%$; or $4,80 \%$ or more positive cells. Intensity and fraction of positive cell scores were multiplied for each marker and thus the scoring system was defined as low expression for scores of $0-4$, and as high expression for scores of $>4$. Two or more coexpression of USCs was regarded as coexpression of USCs. 


\section{Follow-up and Statistical analysis}

All statistical analyses were carried out using the SPSS 16.0 statistical software package (SPSS Inc, Chicago, USA). Follow-up was available for all patients with a median time of 36 months (mean time $=33.1$ months). All patients completed a 5-year follow-up after surgical resection. The recurrence-free survival was calculated as the time from the date of the primary surgery to the date of first recurrence or until last follow-up (8 patients were lost to follow-up). Comparisons between USC expression and tumor locations for statistical significance were carried out with Student $t$ test. The Recurrence-free survival (RFS) was calculated as the time from the date of primary surgery to the date of first recurrence. Survival curves were plotted by the Kaplan-Meier method and compared by the log-rank test. The significance of various variables for survival was analyzed by the Cox proportional hazards model in the multivariate analysis. $\mathrm{P}<$ 0.05 in all cases was considered statistically significant.

\section{Results}

Patient characteristics and tumor location

The median follow-up period of the patients was 33.1 months (range 1-60 months), 84 patients had postoperative recurrent disease. The primary tumor site was in the trigone of bladder in $38(22.5 \%)$ of the patients, in the posterior wall in $50(29.6 \%)$ of the patients, in the left wall in 36 $(21.3 \%)$ of the patients, in the right wall in $26(15.4 \%)$ of the patients, in the anterior wall in $11(6.5 \%)$ of the patients, and in the dome in 8 $(4.7 \% 0$ of the patients.

\section{Patterns of expression}

$\Delta$ Np63 immunoreactivity was nuclear and high expression was observed in 129 cases (76.3\%). Integrin $\quad \beta 4$ immunoreactivity was both membranous and cytoplasmic and high expression was observed in 61 cases (36.1\%). CD47 immunoreactivity was both membranous and cytoplasmic and high expression was observed in 118 cases (69.8\%). CD44v6 immunoreactivity was both membranous and cytoplasmic and was observed in 64 cases (37.9\%). The representative immunostaining of $\triangle \mathrm{Np} 63$, integrin $\beta 4, \mathrm{CD} 47$ and CD44v6 were shown in Fig. 1. Moreover, we investigated the mRNA expression of USC markers in cancers located in

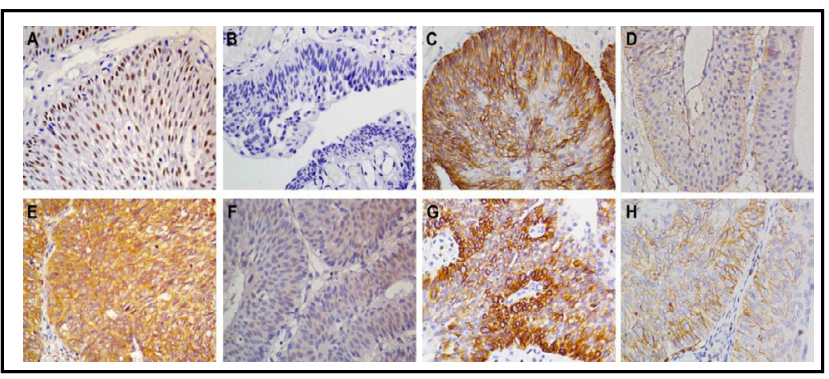

Fig. 1. The expression of $\Delta \mathrm{Np} 63$, integrin $\beta 4, C D 47$, and CD44v6 in NMIBC by immunohistochemistry. A-B, high and low immunoreactivity of $\Delta$ Np63. C-D, high and low immunoreactivity of integrin $\beta 4$. E-F, high and low immunoreactivity of CD47. G-H, high and low immunoreactivity of CD44v6. (original magnification 400x).

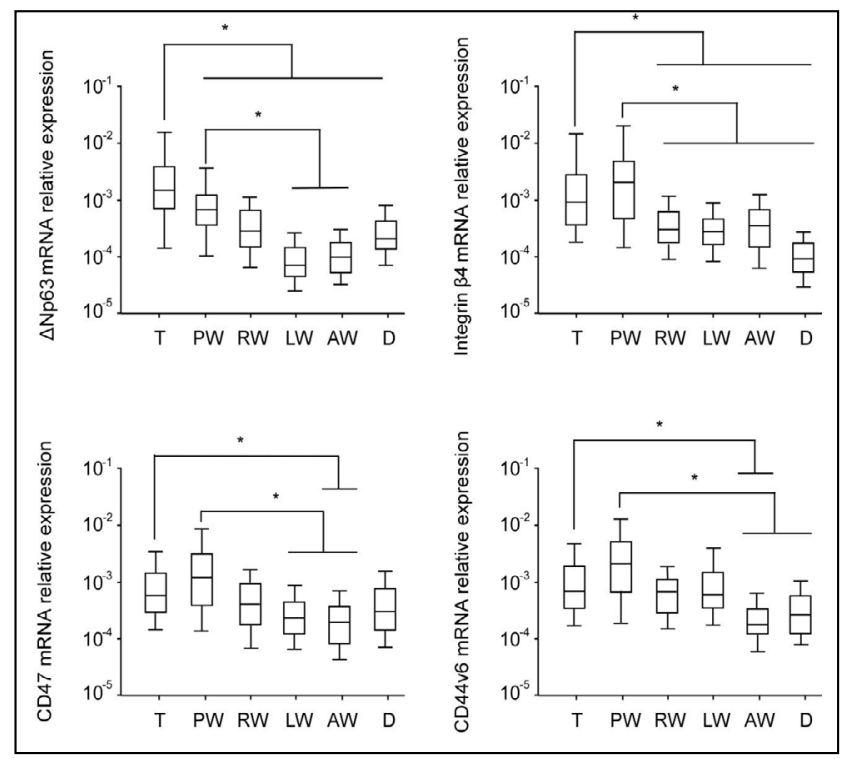

Fig. 2. Relative mRNA expression of $\Delta N p 63$, integrin $\beta 4, C D 47$, and CD44v6 in NMIBC located in different topographic regions of the bladder. T: trigone, PW: posterior wall, RW: right wall, LW: left wall, AW: anterior wall, D: dome. ${ }^{*} \mathrm{P}<0.05$. 
different topographic regions of the bladder by real-time PCR. Strikingly, higher expression levels of USC markers were found in tumors located in the trigone and posterior wall than that in other regions of bladder (Fig. 2).

\section{Associations between \\ USC markers expression \\ and clinicopathological variables}

The expression of $\Delta \mathrm{Np} 63$, integrin $\beta 4, \mathrm{CD} 47$, and CD44v6 was evaluated in relation to clinicopathological features for NMIBC. The results showed that $\Delta \mathrm{Np63}$ expression was positively correlated with tumor stage $(\mathrm{P}=0.023)$ and tumor size $(\mathrm{P}=0.001)$, and that integrin $\beta 4$ expression was significantly associated with tumor stage $(\mathrm{P}=0.026)$, tumor grade $(\mathrm{P}=0.005)$ and tumor size $(\mathrm{P}=0.003)$. CD47, and CD44v6 expression was not associated with any of the clinicopathological variables (Table 1). Furthermore, Integrin $\beta 4$, CD 47 , and CD44v6 expression were significantly associated with cancer recurrence $(\mathrm{P}=0.032, \mathrm{P}=0.010$, and $\mathrm{P}=0.043$, respectively), while $\Delta \mathrm{Np63}$ expression was not correlated with tumor recurrence (Table 2).

\section{Associations between USC markers expression and clinical prognosis}

To examine the prognostic role of USC markers in bladder cancer, we evaluated the correlation of $\triangle \mathrm{Np} 63$, integrin $\beta 4, \mathrm{CD} 47$, and CD44v6 expression with the RFS in NMIBC patients. The results showed that high expression of integrin $\beta 4, \mathrm{CD} 47$, and CD44v6 $(\mathrm{P}=0.016, \mathrm{P}=0.041$, and $\mathrm{P}=0.043$, respectively, Fig. 3A-3D) were correlated with poor RFS in 169 NMIBC patients. Moreover, patients with coexpression of USCs had significantly shorter RFS in compared with that without USCs coexpression ( $\mathrm{P}=0.02$, Fig. 3E). Notably, high expression of $\triangle \mathrm{Np} 63$ and integrin $\beta 4$ was correlated with poor RFS in NMIBC patients with tumors located in the trigone ( $\mathrm{P}=0.025$ and $\mathrm{P}=0.023$, respectively, Fig. $4 \mathrm{~A})$. Additionally, high expression of integrin $\beta 4, C D 47$, and CD $44 \mathrm{v} 6$ was correlated with poor RFS in NMIBC patients with tumors located in the posterior wall $(\mathrm{P}=0.017, \mathrm{P}=0.033$ and $\mathrm{P}=0.047$, respectively, Fig. $4 \mathrm{~B})$. When combining the trigone and posterior wall areas, patients with tumors exhibiting higher integrin $\beta 4$ and CD47 expression had a significantly shorter RFS ( $P=0.002$ and $\mathrm{P}=0.005$, respectively, Fig. $4 \mathrm{C}$ ). Multivariate analysis indicated that high integrin $\beta 4$ and CD47 expression were independent prognostic factors of NMIBC patient's RFS (P=0.003 and $P=0.010$, respectively, Table 3 ), while high $\Delta N p 63$, integrin $\beta 4$, and CD47 expression could be used as independent prognostic factors for trigone/posterior wall subgroup patients $(\mathrm{P}=0.002, \mathrm{P}<0.001$, and $\mathrm{P}<0.001$, respectively, Table 3 ). 

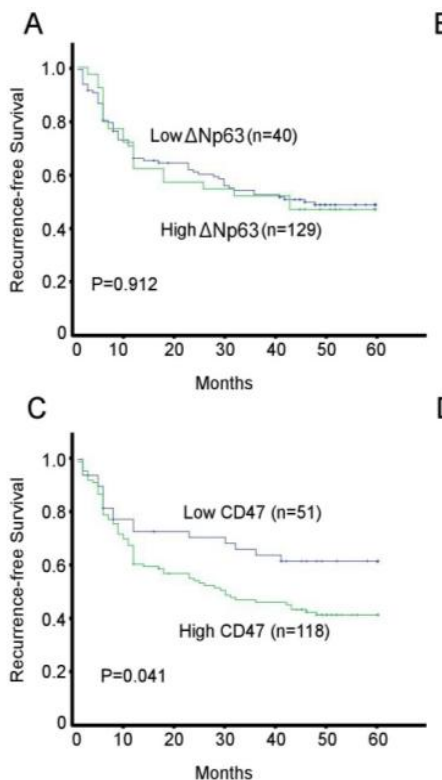

B

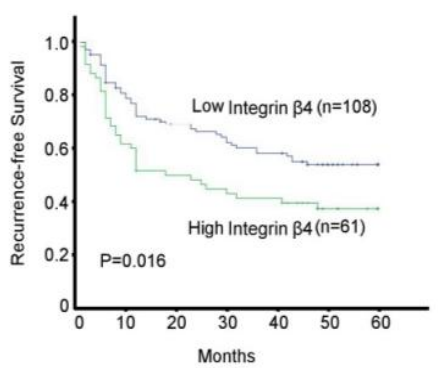

D

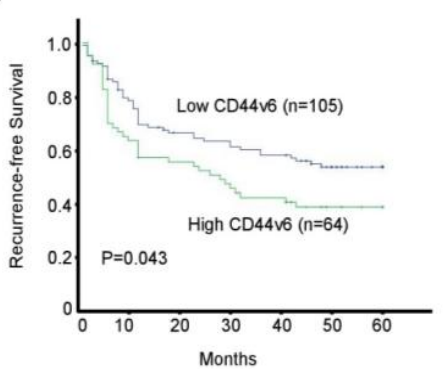

$\mathrm{E}$

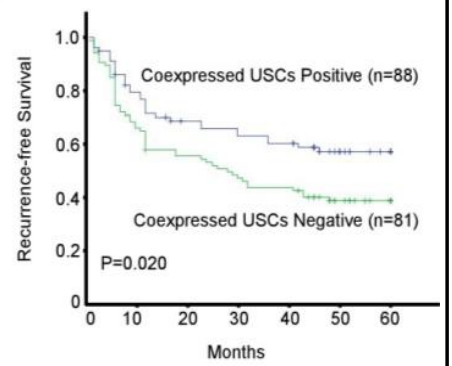

Fig. 3. USC markers expression is associated with prognosis of NMIBC. Kaplan-Meier estimated of recurrence-free survival according to $\Delta \mathrm{Np} 63$ (A), integrin $\beta 4$ (B), CD47 (C), CD44v6 (D) expression, and USCs coexpression (E) in 169 NMIBC patients.

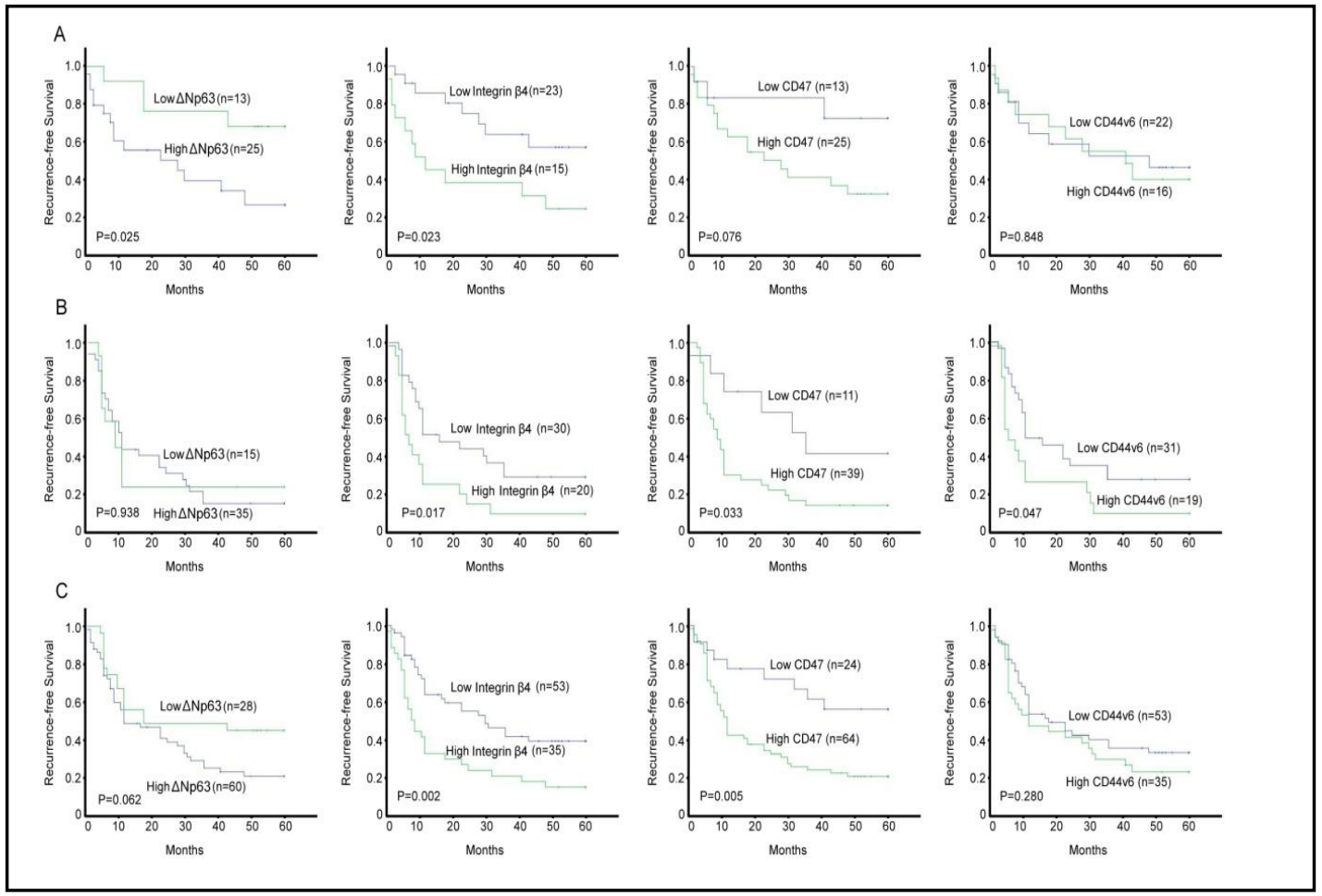

Fig. 4. USC markers expression is associated with prognosis of NMIBC in different regions. Kaplan-Meier survival curves comparing cumulative recurrence-free survival rates in patients with low and high USC markers expression levels in the trigone (A), posterior wall (B), and trigone/posterior wall area (C). 


\section{Cellular Physiology Cell Physiol Biochem 2018;48:2364-2373 \begin{tabular}{ll|l} 
and Biochemistry Published online: 15 August, 2018 & $\begin{array}{l}\text { (c) } 2018 \text { The Author(s). Published by S. Karger AG, Basel } \\
\text { www.karger.com/cpb }\end{array}$ \\
\hline
\end{tabular}}

Table 3. Multivariate analysis of recurrence-free survival. Trigone, PW: Posterior wall

\begin{tabular}{lcccc}
\hline Prognostic variables & $\begin{array}{c}\text { Total } \\
\text { Hazard ratio (95\% CI) }\end{array}$ & $\mathrm{P}$ & Hazard ratio (95\% CI) & $\mathrm{P}$ \\
\hline Sex (M vs F) & $1.124(0.630-2.004)$ & 0.692 & $1.013(0.512-2.008)$ & 0.970 \\
Age (>60 vs $\leq 60)$ & $1.022(0.638-1.637)$ & 0.927 & $1.021(0.580-1.799)$ & 0.942 \\
Tumor Stage (T1 vs Ta) & $1.407(0.850-2.327)$ & 0.184 & $1.493(0.752-2.965)$ & 0.253 \\
Tumor Grade (high vs low) & $1.022(0.610-1.711)$ & 0.935 & $1.648(0.807-3.368)$ & 0.171 \\
Timor Size ( $\geq 3 \mathrm{~cm}$ vs & $1.786(0.998-3.197)$ & 0.051 & $1.020(0.500-2.080)$ & 0.956 \\
$<3 \mathrm{~cm})$ & $1.286(0.746-2.217)$ & 0.365 & $0.386(0.210-0.710)$ & 0.002 \\
$\Delta$ Np63 (high vs low) & $1.952(1.253-3.093)$ & 0.003 & $2.566(1.520-4.333)$ & $<0.001$ \\
Integrin $\beta 4$ (high vs low) & $2.023(1.185-3.455)$ & 0.010 & $4.117(1.965-8.625)$ & $<0.001$ \\
CD47 (high vs low) & $1.353(0.839-2.181)$ & 0.215 & $1.520(0.839-2.752)$ & 0.167 \\
CD44v6 (high vs low) & & & &
\end{tabular}

\section{Discussion}

USC markers have attracted considerable attention in tumor diagnostic and prognostic implications. Understanding the tumor characteristics according to the position of the primary tumor in the bladder may help improving our knowledge of urothelial tumor biology and the design of treatment protocol. In the present work, we provide the first link between the expression of four USC markers ( $\triangle \mathrm{Np} 63$, integrin $\beta 4, \mathrm{CD} 47$, and CD44v6) and the clinical characteristics of bladder cancer patients. We also investigate the expression of USC markers in relation to the tumor recurrence in terms of the different regions of bladder.

It has been suggested that epithelial stem cells are usually clustered in association with a specialized niche [23]. For example, hair follicle stem cells has been found to locate in the bulge region of the follicle, and corneal epithelial stem cells are proposed to be located in the basal layer of the limbal epithelium [23]. Likewise, several studies support the existence of different urothelial lineages governed by their own population of stem cells in the bladder. First, it is generally known that the bladder epithelium is derived from endoderm, while bladder trigone urothelium is mesoderm or endoderm derived has been controversial [24]. Recent evidence showed that trigone derives mostly from the rest of the bladder with a more minor contribution from the ureter, or Wolffian ducts or a combination of both [25]. Second, the initial occurrences of hyperplastic changes at different anatomical sites of bladder are different. For example, Wiener et al. found that the most predominant subsites of Brunn's nests and cystitis cystica in bladder are trigone $(79.8 \%$ and $73.3 \%)$, bladder neck (68.5\% and 53.3\%), and posterior wall (65.2\% and 30\%) [26]. Similarily, more than $80 \%$ of nonkeratinizing squamous metaplasias were discovered in bladder neck and trigone [27]. Third, the initial occurrences of TCC in different bladder subsites were compared as well. Carcinoma of lateral walls and posterior wall are the most frequent sites of origin of TCC, accounting for $37.8 \%$ and $17.6 \%$, respectively [28]. These studies suggested that these distinct populations of urothelial stem cells at different anatomical sites may play roles in giving rise to different population of urothelial tumors. Our study showed that tumors in the trigone and posterior wall exhibited higher levels of USC markers, indicating that a high concentration of stem cells may be involved in the tumorigenesis of TCC in bladder trigone and posterior wall.

Although SC markers have been used to predict the clinical survival in cancer patients, the expression of SC markers may exhibit heterogeneity between the subtypes of malignancies. For example, CD44+/CD24- appear to an independent indicator of tumor invasiveness and recurrence in breast cancer [29], while CD44+/CD24- expression varied between breast cancer cell lines and between primary tumors, and it was not universally enriched in breast cancer stem cells [30]. Similarly, ALDH1A1 expression is strongly associated with prognosis in patients with lung adenocarcinoma, while its expression in papillary predominant adenocarcinoma was significantly higher than those of solid predominant adenocarcinoma 


\section{Cellular Physiology Cell Physiol Biochem 2018;48:2364-2373 \begin{tabular}{l|l} 
DOI: 10.1159/000492652 & $\begin{array}{l}\text { O } 2018 \text { The Author(s). Published by S. Karger AG, Basel } \\
\text { www.karger.com/cpb }\end{array}$
\end{tabular} \\ Wang et al.: USC Markers Predict RFS of NMIBC in Different Areas}

[31]. An identical heterogeneity in a manner analogous has also been described for leukaemic stem cells [32]. Our results showed diverse USC markers expression levels in bladder cancer located in different topographic regions, indicating that heterogeneous population of bladder cancer cells may exhibit different tumorigenicity and malignancy potentials.

Interestingly, we found that the prognostic significance of USC markers differs according to the location of tumors. Several assumptions are still controversial in the roles of SC markers in tumorigenesis and predicting prognosis. For example, high expression of P63 has been showed to be correlated significantly with shorter survival in gastric cancer patients [33], while it was correlated with good prognosis in lung squamous cell carcinoma patients [34]. Likewise, integrin $\alpha 6 \beta 4$ has been shown to mediate an adhesion-independent tumorsuppressive effect or act as a tumor promoter in squamous cell carcinomas [35]. Together these findings underline the high extent of bladder cancer heterogeneity.

Studies addressing the prognostic significance of primary tumor location in cancers have shown conflicting results. Kroman et al. demonstrated that the clinical survival is significantly better for patients with a tumor in the upper lateral quadrant than that located elsewhere in the breast [36]. Hemminki et al. reported that tumor location of colorectal cancer was closely related to TNM classes and survival [37]. Conversely, Li et al. demonstrated that tumor location cannot be used to predict oncologic outcomes in patients with primary ureteral urothelial carcinoma [38]. Even in patients with bladder cancer, the impact of tumor location on prognosis is still controversial. Vukomanovic et al. showed that tumor location is a prognostic factor for recurrence in patients with high-grade NMIBC [39], while study from Deng et al. indicated that tumor location may not be suitable to predict the recurrence of NMIBC [40]. Our study suggested that the prognostic significance of tumor location in NMIBC is depend on SC markers expression status. This finding may explain the diverse results reported in the literature.

Our study has 2 limitations. First, this is a retrospective study, hence there are unknown factors that may be related to clinical prognosis and were not included when we collected the data. Second, this was based on one cohort study, and additional studies on larger participant populations of more cohorts are required to confirm these preliminary findings.

\section{Conclusion}

In conclusion, we provided the first clinical evidence that USC markers could be used as prognostic markers for NMIBC patients. More importantly, we found that high expression of $\Delta \mathrm{Np} 63$ and integrin $\beta 4$ is correlated with poor prognosis in the trigone tumor group, while high expression of integrin $\beta 4, \mathrm{CD} 47$, and CD44v6 predict poor prognosis for patients with cancers located in the posterior wall. The findings of our study may shed light on the prevention of bladder cancer recurrence. Patients with positive USC markers expression, especially with USCs coexpression, may need more frequent intravesical chemotherapy and cystoscopy surveillance postoperatively.

Further studies are needed to investigate the mechanism of recurrence and treatment effects of bladder cancer stratified by tumor location, which may lead to new treatment strategies for bladder cancer.

\section{Acknowledgements}

The study was supported by the National Natural Science Foundation of China (Grant No. 81772714). 


\section{Cellular Physiology Cell Physiol Biochem 2018;48:2364-2373 \begin{tabular}{ll|l} 
and Biochemistry Published online: 15 August, 2018 & $\begin{array}{l}\text { (c) } 2018 \text { The Author(s). Published by S. Karger AG, Basel } \\
\text { www.karger.com/cpb }\end{array}$
\end{tabular}}

\section{Disclosure Statement}

No conflict of interests exists.

\section{References}

$>1$ Torre LA, Bray F, Siegel RL, Ferlay J, Lortet-Tieulent J, Jemal A: Global cancer statistics, 2012. CA Cancer J Clin 2015;65:87-108.

-2 Li HJ, Sun XM, Li ZK, Yin QW, Pang H, Pan JJ, Li X, Chen W: LncRNA UCA1 Promotes Mitochondrial Function of Bladder Cancer via the MiR-195/ARL2 Signaling Pathway. Cell Physiol Biochem 2017;43:2548-2561.

-3 Griffiths TR, Action on Bladder C: Current perspectives in bladder cancer management. Int J Clin Pract 2013;67:435-448.

-4 Xiong Y, Wang L, Li Y, Chen M, He W, Qi L: The Long Non-Coding RNA XIST Interacted with MiR-124 to Modulate Bladder Cancer Growth, Invasion and Migration by Targeting Androgen Receptor (AR). Cell Physiol Biochem 2017;43:405-418.

5 Ajani JA, Song S, Hochster HS, Steinberg IB: Cancer stem cells: the promise and the potential. Semin Oncol 2015;42:S3-17.

6 Shang A, Yang M, Shen F, Wang J, Wei J, Wang W, Lu W, Wang C, Wang C: MiR-1-3p Suppresses the Proliferation, Invasion and Migration of Bladder Cancer Cells by Up-Regulating SFRP1 Expression. Cell Physiol Biochem 2017;41:1179-1188.

7 Wu XR, Kong XP, Pellicer A, Kreibich G, Sun TT: Uroplakins in urothelial biology, function, and disease. Kidney Int 2009;75:1153-1165.

-8 Khandelwal P, Abraham SN, Apodaca G: Cell biology and physiology of the uroepithelium. Am J Physiol Renal Physiol 2009;297:F1477-1501.

-9 Hatina J, Schulz WA: Stem cells in the biology of normal urothelium and urothelial carcinoma. Neoplasma 2012;59:728-736.

10 Van Batavia J, Yamany T, Molotkov A, Dan H, Mansukhani M, Batourina E, Schneider K, Oyon D, Dunlop M, Wu XR, Cordon-Cardo C, Mendelsohn C: Bladder cancers arise from distinct urothelial sub-populations. Nat Cell Biol 2014;16:982-991, 1-5.

11 Li P, Yang X, Cheng Y, Zhang X, Yang C, Deng X, Li P, Tao J, Yang H, Wei J, Tang J, Yuan W, Lu Q Xu X, Gu M: MicroRNA-218 Increases the Sensitivity of Bladder Cancer to Cisplatin by Targeting Glut1. Cell Physiol Biochem 2017;41:921-932.

12 Pignon JC, Grisanzio C, Geng Y, Song J, Shivdasani RA, Signoretti S: p63-expressing cells are the stem cells of developing prostate, bladder, and colorectal epithelia. Proc Natl Acad Sci U S A 2013;110:8105-8110.

13 Koga F, Kawakami S, Kumagai J, Takizawa T, Ando N, Arai G, Kageyama Y, Kihara K: Impaired Delta Np63 expression associates with reduced beta-catenin and aggressive phenotypes of urothelial neoplasms. Br J Cancer 2003;88:740-747.

14 Kurzrock EA, Lieu DK, Degraffenried LA, Chan CW, Isseroff RR: Label-retaining cells of the bladder: candidate urothelial stem cells. Am J Physiol Renal Physiol 2008;294:F1415-1421.

15 Mialhe A, Louis J, Pasquier D, Rambeaud JJ, Seigneurin D: Expression of three cell adhesion molecules in bladder carcinomas: correlation with pathological features. Anal Cell Pathol 1997;13:125-136.

-16 Chan KS, Espinosa I, Chao M, Wong D, Ailles L, Diehn M, Gill H, Presti J, Jr., Chang HY, van de Rijn M, Shortliffe L, Weissman IL: Identification, molecular characterization, clinical prognosis, and therapeutic targeting of human bladder tumor-initiating cells. Proc Natl Acad Sci U S A 2009;106:14016-14021.

17 Yang YM, Chang JW: Bladder cancer initiating cells (BCICs) are among EMA-CD44v6+ subset: novel methods for isolating undetermined cancer stem (initiating) cells. Cancer Invest 2008;26:725-733.

18 Sanchez Freire V, Burkhard FC, Schmitz A, Kessler TM, Monastyrskaya K: Structural differences between the bladder dome and trigone revealed by mRNA expression analysis of cold-cut biopsies. BJU Int 2011;108:E126-135.

19 Fan B, Zhang X, Ma Y, Zhang A: Fangchinoline Induces Apoptosis, Autophagy and Energetic Impairment in Bladder Cancer. Cell Physiol Biochem 2017;43:1003-1011.

20 Nguyen MM, Lieu DK, deGraffenried LA, Isseroff RR, Kurzrock EA: Urothelial progenitor cells: regional differences in the rat bladder. Cell Prolif 2007;40:157-165. 


\section{Cellular Physiology Cell Physiol Biochem 2018;48:2364-2373 \begin{tabular}{ll|l} 
and Biochemistry Published online: 15 August, 2018 & $\begin{array}{l}\text { (c) } 2018 \text { The Author(s). Published by S. Karger AG, Basel } \\
\text { www.karger.com/cpb }\end{array}$
\end{tabular}}

-21 Wojtczyk-Miaskowska A, Presler M, Michajlowski J, Matuszewski M, Schlichtholz B: Gene Expression, DNA Methylation and Prognostic Significance of DNA Repair Genes in Human Bladder Cancer. Cell Physiol Biochem 2017;42:2404-2417.

22 Chen Y, Peng Y, Xu Z, Ge B, Xiang X, Zhang T, Gao L, Shi H, Wang C, Huang J: LncROR Promotes Bladder Cancer Cell Proliferation, Migration, and Epithelial-Mesenchymal Transition. Cell Physiol Biochem 2017;41:2399-2410.

-23 Lavker RM, Sun TT: Epidermal stem cells: properties, markers, and location. Proc Natl Acad Sci U S A 2000;97:13473-13475.

-24 Baker LA, Gomez RA: Embryonic development of the ureter. Semin Nephrol 1998;18:569-584.

-25 Viana R, Batourina E, Huang H, Dressler GR, Kobayashi A, Behringer RR, Shapiro E, Hensle T, Lambert $\mathrm{S}$, Mendelsohn C: The development of the bladder trigone, the center of the anti-reflux mechanism. Development 2007;134:3763-3769.

26 Wiener DP, Koss LG, Sablay B, Freed SZ: The prevalence and significance of Brunn's nests, cystitis cystica and squamous metaplasia in normal bladders. J Urol 1979;122:317-321.

27 Khan MS, Thornhill JA, Gaffney E, Loftus B, Butler MR: Keratinising squamous metaplasia of the bladder: natural history and rationalization of management based on review of 54 years experience. Eur Urol 2002;42:469-474.

28 Stephenson WT, Holmes FF, Noble MJ, Gerald KB: Analysis of bladder carcinoma by subsite. Cystoscopic location may have prognostic value. Cancer 1990;66:1630-1635.

29 Lin Y, Zhong Y, Guan H, Zhang X, Sun Q: CD44+/CD24- phenotype contributes to malignant relapse following surgical resection and chemotherapy in patients with invasive ductal carcinoma. J Exp Clin Cancer Res 2012;31:59.

-30 Hwang-Verslues WW, Kuo WH, Chang PH, Pan CC, Wang HH, Tsai ST, Jeng YM, Shew JY, Kung JT, Chen CH, Lee EY, Chang KJ, Lee WH: Multiple lineages of human breast cancer stem/progenitor cells identified by profiling with stem cell markers. PLoS One 2009;4:e8377.

-31 Shimada Y, Saji H, Nomura M, Matsubayashi J, Yoshida K, Kakihana M, Kajiwara N, Ohira T, Ikeda N: Cancer stem cell-related marker expression in lung adenocarcinoma and relevance of histologic subtypes based on IASLC/ATS/ERS classification. Onco Targets Ther 2013;6:1597-1604.

32 Hope KJ, Jin L, Dick JE: Acute myeloid leukemia originates from a hierarchy of leukemic stem cell classes that differ in self-renewal capacity. Nat Immunol 2004;5:738-743.

33 Song Y, Liu D, He G: TKTL1 and p63 are biomarkers for the poor prognosis of gastric cancer patients. Cancer Biomark 2015;15:591-597.

34 Ma Y, Fan M, Dai L, Kang X, Liu Y, Sun Y, Xiong H, Liang Z, Yan W, Chen K: Expression of p63 and CK5/6 in early-stage lung squamous cell carcinoma is not only an early diagnostic indicator but also correlates with a good prognosis. Thorac Cancer 2015;6:288-295.

-35 Raymond K, Kreft M, Song JY, Janssen H, Sonnenberg A: Dual Role of alpha6beta4 integrin in epidermal tumor growth: tumor-suppressive versus tumor-promoting function. Mol Biol Cell 2007;18:4210-4221.

- 36 Kroman N, Wohlfahrt J, Mouridsen HT, Melbye M: Influence of tumor location on breast cancer prognosis. Int J Cancer 2003;105:542-545.

-37 Hemminki K, Santi I, Weires M, Thomsen H, Sundquist J, Bermejo JL: Tumor location and patient characteristics of colon and rectal adenocarcinomas in relation to survival and TNM classes. BMC Cancer 2010;10:688.

-38 Li WM, Wu WJ, Li CC, Ke HL, Wei YC, Yeh HC, Chou YH, Huang CH, Huang CN: The effect of tumor location on prognosis in patients with primary ureteral urothelial carcinoma. Urol Oncol 2013;31:1670-1675.

39 Vukomanovic I, Colovic V, Soldatovic I, Hadzi-Djokic J: Prognostic significance of tumor location in highgrade non-muscle-invasive bladder cancer. Med Oncol 2012;29:1916-1920.

40 Deng N, Chen JX, Chen LW, Qiu SP, Li XF, Wang DH: Shorter recurrence-free survival time, higher risk of multiple recurrences: a retrospective study of non-muscle invasive bladder cancer after transurethral resection. Chin Med J (Engl) 2012;125:3681-3686. 